\title{
Distribution of OV-TL 3 and MOv18 in normal and malignant ovarian tissue
}

\author{
M R Buist, C F M Molthoff, P Kenemans, C J L M Meijer
}

Department of

Obstetrics and

Gynaecology, Free

University Hospital,

De Boelelaan 1117,

1081 HV Amsterdam,

The Netherlands

M R Buist

C F M Molthoff

$P$ Kenemans

Department of

Pathology

C J L M Meijer

Correspondence to: Dr M R Buist.

Accepted for publication 20 December 1994

\begin{abstract}
Aims-To analyse the distribution of $\mathrm{OV}$ TL 3 and MOv18 in normal ovarian tissue to determine which antibody is most suitable for (radio)immunotherapy of ovarian carcinoma.

Methods-The distribution of OV-TL 3 and MOv18 was determined using immunohistochemistry and flow cytometry. Results-Epithelial and other cells in many tissues, and leucocytes in peripheral blood, bone marrow and spleen stained positively with OV-TL 3 . The staining pattern of MOv18 in normal tissues was more restricted and was confined to epithelial cells in the lung, kidney, pancreas, salivary gland, ovary, Fallopian tubes, and cervix. Reactivity was also observed with pneumocytes in the lung, tubuli in the kidney, acinar cells in the salivary gland and pancreas, in the placenta, and with Kupffer cells in the liver. The staining pattern of chimeric MOv18 was identical with the murine form. OV-TL 3 and MOv18 reacted with $100 \%$ and $98 \%(45 / 46)$ of the 46 tested epithelial ovarian cancers, respectively. In ovarian carcinoma tissue homogeneous staining of epithelial cells was observed with OV-TL 3 and more heterogeneous staining with MOv18. In 12 and nine patients, respectively, a difference in staining intensity for OV-TL 3 and MOv18 was observed between various tumour samples from the same patient.

Conclusion-MOv18 has greater therapeutic potential because of its restricted reactivity with normal tissues and especially, in contrast to OV-TL 3, its lack of reactivity with haematopoietic cells.

(f Clin Pathol 1995;48:631-636)
\end{abstract}

Keywords: Ovarian carcinoma, antigen expression, targeting.

ovarian carcinoma. ${ }^{79}$ The antigen recognised by OV-TL 3, OA3, was identified as a novel multimembrane spanning protein, ${ }^{10}$ whereas the antigen recognised by MOv18 is a membrane associated, folate binding protein (FBP). ${ }^{1112}$ In monoclonal antibody based immunotherapy in which the antibody is used alone, or conjugated to toxins, drugs or radionuclides, the reactivity with normal tissues has to be limited to avoid non-specific targeting of normal tissues. Staining with OV-TL 3 was reported to be negative in normal tissues, except for weak and irregular reactivity in some ovarian cysts and in epithelial cells lining the female genital tract. ${ }^{1}$ Normal bone marrow and blood cells were not studied. In the initial report MOv18 showed no reactivity with normal tissues, ${ }^{2}$ but Stein et al reported reactivity with the epithelium of renal tubules, pancreas, lung, salivary glands, Fallopian tubes, and endocervix. ${ }^{13}$

In the present study we have analysed the normal tissue distribution of OV-TL 3, m-MOv18 and c-MOv18 more extensively to select the most appropriate antibody for (radio)immunotherapy of ovarian carcinoma. Primary tumours and metastases of 46 patients with ovarian carcinoma were also examined using immunohistochemistry.

\section{Methods}

MONOCLONAL ANTIBODIES

OV-TL 3 is a murine IgG 1 monoclonal antibody that reacts with an antigen which is highly expressed on $90 \%$ of ovarian carcinomas of different histological types. ${ }^{14-16}$ MOv18 is also of the IgG1 subclass and the antigenic determinants recognised by MOv18 are abundantly present on the cell surface of ovarian carcinoma cells. ${ }^{2}$ Monoclonal antibody OC 125, which recognises the ovarian carcinoma associated CA125 antigen, was used as a control antibody for the intensity of staining of ovarian carcinoma tissues. ${ }^{17}$ OV-TL 3 , mMOv18, c-MOv18, and OC 125 were kindly provided by Dr S O Warnaar (Centocor, Leiden, The Netherlands). MOPC-21 (IgG1; Organon Teknika, Boxtel, The Netherlands) or anti-KLH (IgG1; Becton Dickinson, Erembodegem, Belgium), both directed against non-human antigens, were used as negative controls. applied in pre-clinical and clinical immunotargeting studies. ${ }^{3-7}$ The murine monoclonal antibody MOv18 (m-MOv18) has been chimerised by fusing the murine variable part with the human constant IgG1 region to reduce immunogenicity. ${ }^{8}$ Chimeric MOv18 (cMOv18) has been studied in a xenograft murine model and in patients suspected of having
TISSUE

Normal human tissues were obtained at surgery and snap frozen in liquid nitrogen. Sections 6 $\mu \mathrm{m}$ thick were cut on a cryostat, fixed with 
acetone for 10 minutes at room temperature, air dried and stored at $-80^{\circ} \mathrm{C}$ until analysis. Normal tissues obtained from different individuals were tested. In addition, 156 biopsy specimens of ovarian carcinoma, taken from different locations, were obtained at surgery from 46 patients who underwent laparotomy for ovarian carcinoma. Eighteen patients underwent primary debulking surgery and 28 underwent laparotomy after initial surgery and chemotherapy for ovarian carcinoma. All but one patient had advanced ovarian carcinoma at the time of surgery. One patient with primary ovarian carcinoma had FIGO (Féderation Internationale de Gynaecologie et Obstetrique) stage Ic disease. If present, tissue was obtained from the malignant ovary, as well as from peritoneal metastases. All tissues were processed as described for normal tissues. Samples were assessed histopathologically for determination of the histological type and differentiation grade. Of the 46 ovarian carcinomas, 40 were serous, three were mucinous, two were endometroid ovarian carcinomas, and one tumour was of the clear cell type.

\section{IMMUNOHISTOCHEMISTRY}

Tissue sections were washed in phosphate buffered saline (PBS) and incubated with the monoclonal antibody for 60 minutes at room temperature. After washing, the sections were incubated with peroxidase conjugated rabbit antimouse immunoglobulin (ITK Diagnostics, Uithoorn, The Netherlands) for 30 minutes. The staining reaction was developed by incubating the sections for five to 10 minutes with $0.05 \% \quad(w / v) \quad 3^{\prime}-3^{\prime}$-diaminobenzidine tetrahydrochloride (DAB) in PBS, containing $0.02 \%$ hydrogen peroxide (Sigma, St Louis, Missouri, USA). The sections were washed in PBS, counterstained with haematoxylin and mounted in Depex. Various concentrations of purified OV-TL 3, m-MOv18 and c-MOv18 were studied on control sections of an ovarian carcinoma $(2,10,20,50$, and $100 \mu \mathrm{g} / \mathrm{ml})$. The optimal concentration was determined to be $50 \mu \mathrm{g} / \mathrm{ml}$ for purified $\mathrm{m}$ - and c-MOv18 and $20 \mu \mathrm{g} / \mathrm{ml}$ for purified OV-TL 3 . In each assay serial sections of an ovarian carcinoma, known to react with both antibodies, were tested simultaneously. The intensity of the staining reaction, relative to positive staining of OC 125 on malignant ovarian tissues, was scored as follows: strongly positive $(++)$; moderately positive $(+)$; faint/weak $( \pm)$; or negative $(-)$. The extent of staining was also defined as either homogeneous $(>90 \%$ of the epithelial cells positive), heterogeneous (50-90\% positive), or focal staining (10-50\% positive). All sections were analysed by two observers.

\section{FLOW CYTOMETRY}

Fresh peripheral blood was obtained from apparently healthy individuals and bone marrow aspirates from patients without carcinoma. Spleen cells were obtained by homogenising a spleen through a tissue sieve. White blood cells from peripheral blood and bone marrow were prepared by Ficoll-Hypaque gradient centrifugation (Pharmacia, Uppsala, Sweden) and extensively washed in $0.1 \%$ bovine serum albumin (BSA) in PBS (PBS/BSA).

Table 1 Normal tissue reactivity of OV-TL 3 and MOv1 $18^{a}$

\begin{tabular}{|c|c|c|c|c|c|}
\hline Tissue & $\begin{array}{l}\text { No. of } \\
\text { specimens tested }\end{array}$ & Cell type & $O V-T L 3$ staining & Cell type & $\begin{array}{l}\text { MOv18 } \\
\text { staining }\end{array}$ \\
\hline Brain & 2 & White cortex & $t^{\mathrm{c}}$ & & - \\
\hline Peripheral nerve & 3 & Perineurium & + & & - \\
\hline \multirow[t]{2}{*}{ Skin } & 10 & Endothelial cells & + & & - \\
\hline & & Sebaceous glands & + & & \pm \\
\hline Striated muscle & 10 & Hair follicles & \pm & & - \\
\hline $\begin{array}{l}\text { Striated muscle } \\
\text { Peritoneum }\end{array}$ & $\begin{array}{l}10 \\
10\end{array}$ & & - & & - \\
\hline Spleen & $\begin{array}{r}10 \\
3\end{array}$ & & - & & - \\
\hline Lymph node & 10 & Red pulp & $+t^{c}$ & & - \\
\hline Tonsil & 3 & Lymphocytes & $\frac{ \pm}{ \pm c}$ & & $\overline{-}$ \\
\hline Thymus & 3 & Lymphoid tissue & \pm & Stromal cells & \pm \\
\hline Heart & 3 & & 二 & & $=$ \\
\hline \multirow[t]{2}{*}{ Lung } & 3 & Bronchial epithelium & + & & + \\
\hline & & Pneumocytes & - & & \pm \\
\hline Salivary gland & 3 & Serous acini & \pm & & \pm \\
\hline Stomach & 3 & Collecting ducts & \pm & & \pm \\
\hline \multirow{2}{*}{ Colon } & 5 & Goblet cells & + & & - \\
\hline & & Ganglion cells & + & & - \\
\hline \multirow[t]{3}{*}{ Pancreas } & 3 & Ductal epithelium & \pm & & + \\
\hline & & Acini & 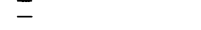 & & + \\
\hline & & Langerhans' cells & \pm & & - \\
\hline Liver & 5 & Kupffer cells & \pm & & \pm \\
\hline \multirow[t]{2}{*}{ Kidney } & 5 & Glomeruli & + & & - \\
\hline & & (Bowman's capsule) & & Distal tubuli & + \\
\hline Bladder & 2 & Transitional cells & \pm & & - \\
\hline Thyroid & 3 & & $\overline{-}$ & & - \\
\hline Adrenal gland & 2 & 2. & - & & - \\
\hline \multirow{2}{*}{ Breast } & 3 & Myoepithelium & \pm & & - \\
\hline & & Lobuli & \pm & & - \\
\hline Ovary & 10 & Follicular epithelium & $\bar{t}$ & & + \\
\hline Fallopian tube & 5 & Epithelial lining & + & & + \\
\hline Uterus & 5 & & - & & - \\
\hline Cervix & 5 & Epithelium & \pm & & \pm \\
\hline Placenta & 1 & Trophoblast & $\overline{+}$ & & $\bar{t}$ \\
\hline Testis & 2 & Rete testis & \pm & & - \\
\hline Prostate & 2 & Epithelium & $\bar{t}$ & & - \\
\hline
\end{tabular}

antensity of staining: ++ , strongly positive; + , moderately positive; \pm , weak/faint;,- no staining. ${ }^{\mathrm{b}}$ The staining pattern for $\mathrm{m}$ - and c-MOv18 was identical. ' Cell type not evaluable because of very high background staining. 

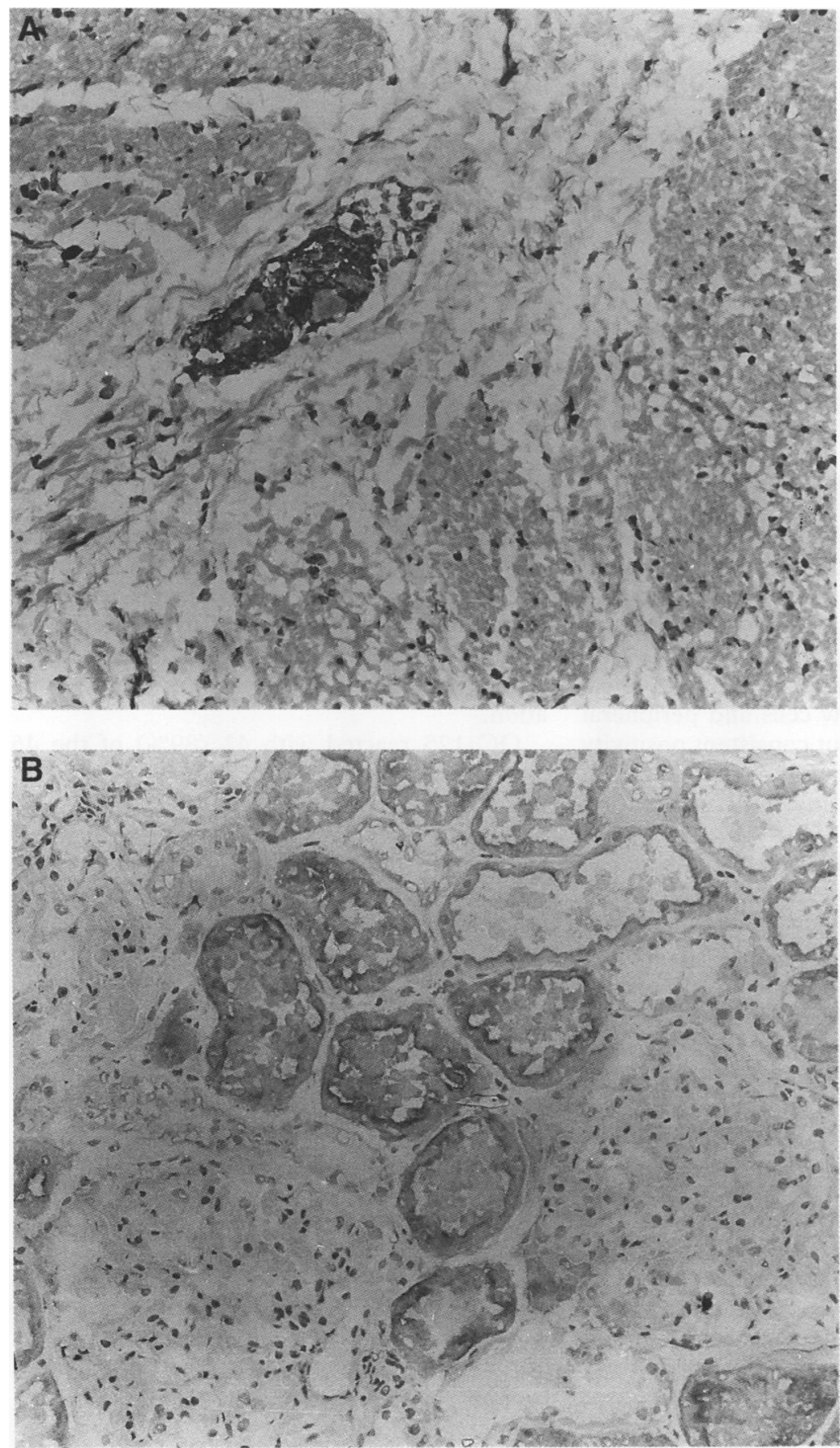

Figure 1 Immunostaining with $O V-T L 3$, showing $(A)$ a positive reaction in the ganglion cells of the large intestine, and with $M O v 18(B)$, showing a positive reaction in the distal tubuli of the kidney. fluorescence of the sample-mean fluorescence of the control)/mean fluorescence of the control).

To classify cells stained positively with OVTL 3, a dual labelling procedure was performed on bone marrow cells and peripheral blood cells. OV-TL 3 was labelled with biotin according to the manufacturer's instructions (NHS-Biotin, Pierce Europe, Oud-Beijerland, The Netherlands). Glycerol (final concentration 50\%) was added and the biotinylated monoclonal antibody was stored frozen at $-20^{\circ} \mathrm{C}$. Dual labelling was performed by incubating cells with $20 \mu \mathrm{g} / \mathrm{ml}$ biotinylated OV-TL 3, followed by an incubation step (45 minutes at $0^{\circ} \mathrm{C}$ ) with $25 \mu \mathrm{g} / \mathrm{ml}$ FITC labelled anti-CD2,-CD3,-CD4,-CD8, -CD14, -CD16, -CD19, -CD34, and -CD38 (Becton Dickinson). Thereafter, cells were incubated for 15 minutes with $5 \mu \mathrm{g} / \mathrm{ml}$ Streptavidin-phycoerythrin (PE). To correct for background fluorescence, the following control samples were included in the procedure: cells incubated with FITC labelled IgG, PE labelled IgG, FITC and PE labelled anti-CDs. Flow cytometry was performed as described earlier.

\section{Results}

NORMAL TISSUE DISTRIBUTION

Twenty eight different normal tissues were analysed for expression of OV-TL 3 and MOv18. The staining patterns found with OV-TL 3, cMOv18, and m-MOv18 are shown in table 1 . Multiple sections of each tissue type were tested and consistent results were obtained in all cases. No difference was observed in staining pattern between murine and chimeric MOv18.

With OV-TL 3, positive staining was observed in various tissue types (table 1). In contrast to the staining pattern of control IgG and MOv18, high background staining was observed in all tissues. A specific cell type or tissue responsible for this background staining could not be identified. In some cases the high background staining prevented reliable evaluation of the staining pattern. Staining with OV-TL 3 was mainly confined to cell membranes, but cytoplasm was stained faintly in almost all cases. OV-TL 3 reacted strongly $(++)$ with the white cortex of the brain and moderately $(+)$ with the perineurium of peripheral nerves. Moderate reactivity was also observed with the endothelial cells and the epithelium of sebaceous glands in the skin. The ciliated epithelium of the bronchi were moderately stained, whereas the pneumocytes were negative. In the intestine both the goblet cells and the plexus located in the submucosa of the intestine and between the longitudinal and inner circular muscle layers were stained positively (fig 1). Positive staining was also observed in the glomeruli of the kidney and transitional cells of the bladder. A positive reaction was also observed in epithelial cells of the normal ovary, the Fallopian tubes, the endometrium, and the cervix. Placental trophoblasts also stained positively. Weak reactivity was observed in some other tissues (table 1). On staining with OV-TL 3 , a positive reaction FITC. After washing, cells were analysed immediately using FACScan (Becton Dickinson). Analysis was performed according to the manufacturer's instructions. ${ }^{18}$ The results were described as fluorescence index $(\mathrm{FI}=$ (mean 
Table 2 FACScan analysis following staining of peripheral blood, bone marrow, and spleen cells of healthy individuals with $O V-T L 3, M O v 18$ and $O C 125$

\begin{tabular}{|c|c|c|c|c|c|c|}
\hline \multirow[b]{2}{*}{ Cell type } & \multicolumn{2}{|c|}{$O V-T L 3$} & \multicolumn{2}{|c|}{ MOv18 } & \multicolumn{2}{|c|}{ OC 125} \\
\hline & $F I$ & Positive cells (\%) & $F I$ & Positive cells (\%) & $F I$ & Positive cells (\%) \\
\hline \multicolumn{7}{|c|}{ Peripheral blood lymphocytes } \\
\hline Mean & $19 \cdot 7$ & $95 \cdot 5$ & 0.2 & 1.9 & 0.6 & $3 \cdot 4$ \\
\hline $\mathrm{SD}$ & $14 \cdot 6$ & $4 \cdot 1$ & $0 \cdot 2$ & $2 \cdot 0$ & $0 \cdot 2$ & 1.5 \\
\hline $\mathrm{n}$ & 2 & 2 & 3 & 3 & 2 & 2 \\
\hline \multicolumn{7}{|c|}{ Bone marrow } \\
\hline Mean & $20 \cdot 3$ & $45 \cdot 8$ & $1 \cdot 0$ & $0 \cdot 7$ & $1 \cdot 3$ & $2 \cdot 8$ \\
\hline SD & $12 \cdot 6$ & $5 \cdot 6$ & $1 \cdot 1$ & $1 \cdot 4$ & 0.9 & $4 \cdot 0$ \\
\hline \multirow{2}{*}{\multicolumn{7}{|c|}{ Spleen }} \\
\hline & & & & & & \\
\hline Mean & $10 \cdot 5$ & $51 \cdot 3$ & 0.6 & 0.6 & $2 \cdot 8$ & $\mathbf{7 \cdot 7}$ \\
\hline $\mathrm{n}$ & 1 & 1 & 1 & 1 & 1 & 1 \\
\hline
\end{tabular}

was observed in lymph nodes, spleen, tonsil, and thymus. Further analysis was performed using flow cytometry. When OV-TL 3 was tested on fresh and fixed cell suspensions of peripheral blood, bone marrow and spleen, a clearly positive staining pattern was observed in leucocytes (table 2). Double staining with OV-TL 3 and the various immunological markers on bone marrow cells and peripheral blood showed variable but consistent positivity in both $\mathrm{T}$ and $\mathrm{B}$ cells (data not shown). Both the granulocyte and erythrocyte fractions were negative.

MOv18 reacted moderately $(+)$ with the ciliated epithelium in the bronchi and weakly $( \pm)$ with the pneumocytes. The ductal epithelium and acinar cells of the pancreas stained positively. Furthermore, reactivity was observed with the distal tubuli in the kidney (fig 1). The follicular epithelium of the ovary, the epithelial lining of the Fallopian tubes, and the placental trophoblasts also stained positively. Weak reactivity $( \pm)$ was evident in some other tissues. In the thymus $10-20 \%$ of stromal cells stained weakly, whereas lymphocytes and Hassall bodies were negative (table 1). In all tissues staining with MOv18 was confined to the cell membrane. On flow cytometry, no immunoreactivity was observed with cells from peripheral blood, bone marrow or spleen.

\section{OVARIAN CARCINOMAS}

OV-TL 3 reacted positively with all $46(100 \%)$ ovarian carcinomas tested. The staining intensity was strong in 33 and moderate in 11 . Staining was very weak in two carcinomas. These tumours were derived from two patients who underwent primary debulking surgery with, respectively, moderately differentiated, mucinous, ovarian carcinoma and well differentiated, endometroid carcinoma of the ovary. In most cases the carcinoma cells were homogeneously stained, with 90 to $100 \%$ of the cells being positive. There was no difference in staining pattern between different tumour deposits from the same patient, although in 12 patients the intensity of staining varied between different peritoneal metastases from faint to strong.

MOv18 reacted with $45(98 \%)$ of the 46 ovarian carcinomas tested. The staining intensity was strong in 41 and moderate in three. Two moderately differentiated mucinous ovarian carcinomas showed very weak and neg- ative staining, respectively. In positive tumours more than $75 \%$ of the tumour cells were stained. In four patients a difference in staining pattern, ranging from negative to moderately or strongly positive, between various peritoneal metastases was observed. In five patients the staining intensity varied from moderately to strongly positive depending on tumour location.

OC 125 reacted with 41 (89\%) of the 46 ovarian carcinomas tested. Staining intensity was strong in 31, moderate in eight and weak in two. Tumours samples from five patients were completely negative, two of whom had recurrent disease diagnosed as poorly differentiated serous ovarian carcinomas, while the remaining three had primary disease diagnosed as well differentiated endometroid, moderately differentiated mucinous and poorly differentiated serous ovarian carcinoma, respectively. The reaction pattern of an ovarian carcinoma tissue section on staining with OV-TL 3, MOv18 and OC 125 is shown in fig 2.

\section{Discussion}

In the present study normal and ovarian carcinoma tissues were analysed for their reactivity with OV-TL 3, m-MOv18 and c-MOv18. OVTL 3 was previously reported by Poels et al to be non-reactive with skin, stomach, prostate, kidney, colon, liver, spleen, lung, and mesothelium. ${ }^{1}$ Weak staining was found in the epithelial lining of the female genital tract such as the endocervix, endometrial glands, Fallopian tubes, and in some ovarian cysts. Our study confirms the reported reactivity in the female genital tract. We also observed reactivity in bronchial epithelium, endothelial and epithelial cells in the skin, goblet cells and ganglion cells in the intestine, ductal and acinar cells in salivary gland and pancreas, Langerhans' cells, Kupffer cells, glomeruli in kidney, transitional cells in the bladder, epithelial cells in breast, placenta, and prostate, brain cells, and peripheral nerves. The discrepancies might be explained by methodological differences. Poels et al used an indirect immunofluorescence assay, with possible fluctuations in specificity. Furthermore, background staining observed with OV-TL 3 might have obscured specific staining in normal tissues.

The gene encoding the OV-TL 3 defined antigen $\mathrm{OA} 3$ was cloned recently. ${ }^{10}$ The antigen 

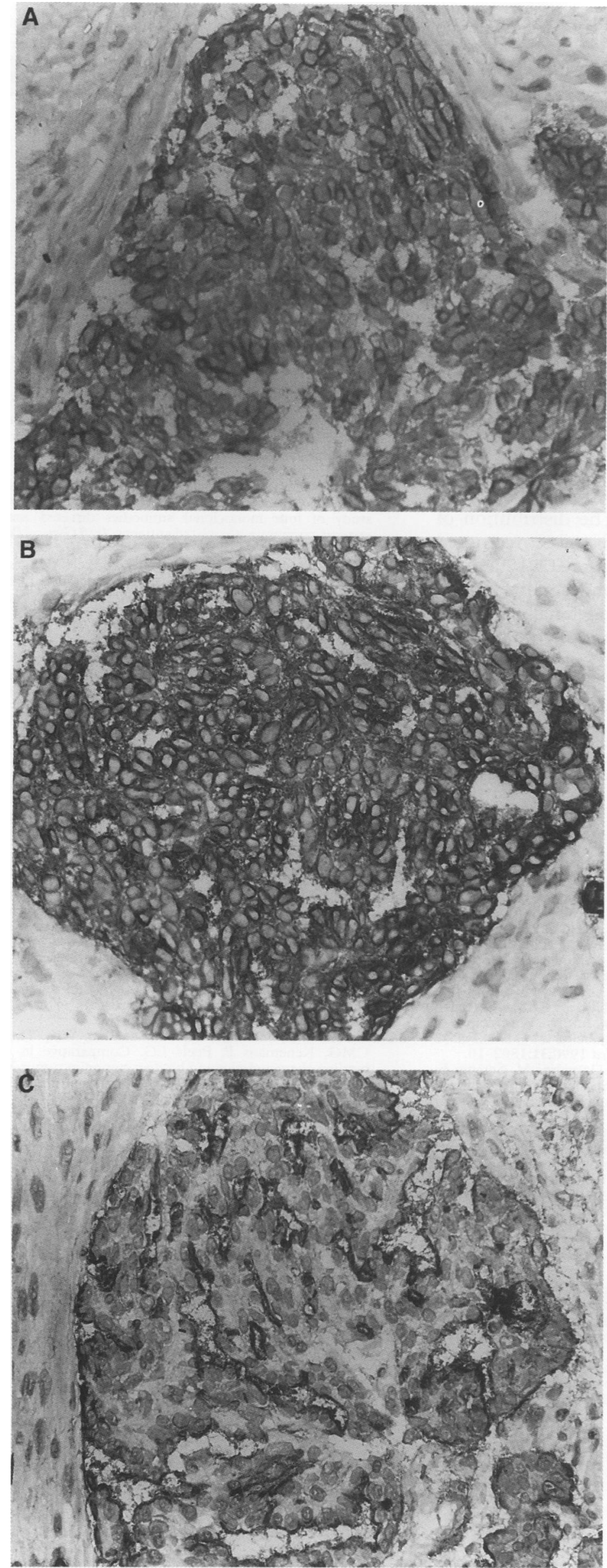

Figure 2 Reactivity of a poorly differentiated ovarian carcinoma tissue section with $O V$ TL 3 showing (A) a heterogeneous pattern and background staining, with MOv18 $(B)$ showing homogeneous staining of the membrane, and with $O C 125(C)$ showing hetergeneous staining of the apical side of the tumour cells. appeared to have a multimembrane spanning domain structure with an as yet unknown function, but which may have a role in membrane transport or signal transduction. On northern blot analysis, the OA3 messenger RNA (mRNA) was found in heart, brain, placenta, lung, liver, skeletal muscle, kidney, and pancreas. ${ }^{10}$ In our immunohistochemical study heart and muscle tissue were negative on staining with OV-TL 3, but these differences could be due to the greater sensitivity of northern blot analysis.

Although m-MOv18 was originally reported to be restricted to ovarian carcinoma, ${ }^{2}$ Stein et al showed immunohistochemical reactivity with ductal epithelium in the pancreas and the salivary glands, with Fallopian tube epithelium, cervical tissue, glandular cells in the bronchus, and with epithelial cells and/or secretions in the lung. ${ }^{13}$ Our findings are in agreement with their data. The antigen recognised by MOv18, abundantly present on ovarian carcinoma cells, is a high affinity FBP. ${ }^{11}{ }^{12}$ Recently, Ross et al measured, using the polymerase chain reaction, the relative mRNA levels for the two known isoforms of FBP. Both forms were present in low to moderate quantities in a wide variety of normal and malignant tissues. More specifically, one of the isoforms was moderately expressed in normal colon, spleen, thymus and placenta, whereas the other isoform was highly expressed in ovarian carcinomas and some other tumours. ${ }^{19}$ Our findings agree substantially with those of Weitman et $a l^{20}$ who used immunohistochemical methods (MOv19) to stain FBP. In contrast to our findings with MOv18, these authors observed positive staining in the proximal tubules of the kidney, the acinar cells in the breast, and focal staining in the thyroid. ${ }^{20}$ Mantovani et $a l^{21}$ demonstrated, on staining with MOv18, intense and moderate staining in the Fallopian tubes and proximal and distal tubules, and weak or focal staining in the oesophagus, stomach, pancreas, mammary gland, and thyroid. Weitman et $a l^{22}$ showed, using immunoblotting and radioimmunoassays, expression of FBP in the choroid plexus, thyroid, kidney, and lung. A possible correlation between MOv18 expression, the two FBP isoforms, and any clinical consequence is as yet unclear.

Radiolabelled OV-TL 3 and MOv18 have been used for radioimmunotargeting in patients with ovarian carcinoma. ${ }^{3469}$ The radiolabelled antibodies localised preferentially in ovarian cancer lesions, as shown by the positive immunoscintigrams and high uptake of radioactivity in tumour tissue compared with uptake in normal tissues, such as skin, muscle, fat, and normal peritoneum. Uptake in normal tissues observed on immunoscintigrams was as expected. No changes in haematological or chemical profiles were observed after injection of radiolabelled OV-TL $3 \mathrm{~F}\left(\mathrm{ab}^{\prime}\right) 2$ or $\mathrm{c}-\mathrm{MOv} 18 .{ }^{69}$ OV-TL 3 was reported to be more useful for immunolocalisation compared with OC 125 because it is more homogeneously distributed within ovarian cancer tissue, the antigen is not shed, and is more favourably distributed in tumour bearing, athymic mice. ${ }^{23-26}$ 
In the present study OV-TL 3, MOv18 and CA 125 reacted with $100 \%, 98 \%$, and $89 \%$ of the carcinomas examined, respectively. For each monoclonal antibody, the sensitivity was higher for serous ovarian carcinomas than with other types. Both findings agree with observations in other studies. ${ }^{151627}$ Heterogeneous staining intensity was observed within different peritoneal metastases of the same patient with all three monoclonal antibodies.

In antibody based immunotherapy, uptake of the monoclonal antibody in normal tissues might be detrimental when a high dose of antibody is required. However, it is unlikely that low level expression of an antigen in normal tissues will elicit side effects if the antibody directed against this antigen is applied clinically. ${ }^{28}$ Nevertheless, with an immunoconjugate based on OV-TL 3, specific damage to leucocytes might cause serious side effects, limiting effective therapy. The distribution of MOv18 in normal tissue is more restricted than that of OV-TL 3, making MOv18 a more suitable candidate for immunotherapy. Therapeutic trials with this monoclonal antibody, however, will have to be carefully planned in view of the staining observed in the lung and kidney.

We thank $R$ von Meier for expert technical assistance and $\mathrm{Dr}$ J Hilgers for critical reading of the manuscript. This work was supported by a clinical research supported by a clinical research grant from the Netherlands by the Biocare Foundation (grant 92-05)

1 Poels LG, Peters D, van Megen Y, Vooijs PG, Veheijen RHM, Willemen A, et al. Monoclonal antibody against human ovarian tumor-associated antigens. 7 Natl Cancer Inst 1986;76:781-7.

2 Miotti S, Canevari S, Menard D, Mezzanzanica D, Porro G, Pupa SM, et al. Characterization of human ovarian carcinoma associated antigens defined by novel monoclonal antibodies with tumor restricted specificity. Int $\mathcal{F}$ Cancer 1987;39:1802-10.

3 Massuger LFAG, Kenemans P, Claessens RAMJ, Verheijen RHM, Schijf CPT, Strijk SP, et al. Immunoscintigraphy of ovarian cancer with indium-111 labeled OV-TL $3\left(\mathrm{Fab}^{\prime}\right) 2$ monoclonal antibody. $f$ Nucl Med 1990;31:1802-10.

4 Crippa F, Buraggi GL, Di Re E, Gasparini M, Seregni E, Canevari S, et al. Radioimmunoscintigraphy of ovarian cancer with the MOv18 monoclonal antibody. Eur f Cancer cancer with the $M$

5 Bolhuis RLH, Lamers CHJ, Goey SH, Eggermont AMM, Trimbos JB, Stoter G, et al. Adoptive immunotherapy of ovarian carcinoma with bs-MAb-targeted lymphocytes. A multicentre study. Int $\mathcal{f}$ Cancer 1992;48(Suppl 7):78-81.

6 Buist MR, Kenemans P, Vermorken JB, Golding RP, Burge $\mathrm{CW}$, den Hollander W, et al. Radioimmunotargeting on ovarian carcinoma patients with indium-111 labeled monoclonal antibody OV-TL $3 \mathrm{~F}\left(\mathrm{ab}^{\prime}\right) 2$ : pharmacokinetics, tissue distribution, and tumor imaging. Int $\mathcal{f}$ Gynecol Cancer 1992;2:23-34.

7 Molthoff CFM, Buist MR, Kenemans P, Pinedo HM, Boven E. Experimental and clinical analysis of the characteristics of a chimeric monoclonal antibody, MOv18, reactive with of a chimeric monoclonal antibody, MOv18, reactive with an ovarian

8 Coney LR, Mezzanzanica D, Sanborn D, Casalini P, Colnaghi MI, Zurawski VR. Chimeric murine-human antibodies directed against folate binding receptor are efficien mediators of ovarian carcinoma cell killing. Cancer Res 1994;54:2448-55.

9 Buist MR, Kenemans P, den Hollander W, Vermorken JB, Molthoff CFM, Burger CW, et al. Kinetics and tissue distribution of the radiolabeled chimeric monoclonal antibody MOv18 and (Fab') 2 fragments in ovarian carcinoma patients. Cancer Res 1993;53:5413-18.

10 Campbell IG, Freemont PS, Foulkes W, Trowsdale J. An ovarian tumor marker with homology to vaccinia virus contains an IgV-like region and multiple transmembrane domains. Cancer Res 1992;52:5416-20.

11 Campbell IG, Jones TA, Foulkes WD, Trowsdale J. Folatebinding protein in a marker for ovarian cancer. Cancer Res binding protein in

12 Coney LR, Tomassetti A, Carayannopoulos L, Frasca V, Kamen BA, Colnaghi MI, et al. Cloning of a tumorassociated antigen: MOv18 and MOv19 antibodies recognize a folate-binding protein. Cancer Res 1991;51: 6125-35.

13 Stein R, Goldenberg DM, Mattes MJ. Normal tissue reactivity of four anti-tumor monoclonal antibodies of clinical interest. Int $\mathcal{f}$ Cancer 1991;47:163-9.

14 Henzen-Logmans SC, Schipper NW, Poels LG, Kenemans $P$, Meyer CJLM. Use of statistical evaluation of antigen profiles in differential diagnosis between colonic and

15 Berchuck A, Olt GJ, Soisson AP, Kanel A, Soper JT, Boyer $\mathrm{CM}$, et al. Heterogeneity of antigen expression in advanced epithelial ovarian cancer. Am $\mathscr{f}$ Obstet Gynecol 1990;162: 883-8.

16 Boerman OC, van Niekerk CC, Makkink WK, Hanselaar AGJM, Kenemans P. Comparative immunohistochemical study of four monoclonal antibodies directed against ovarian carcinoma-associated antigens. Int $\mathcal{F}$ Gynecol Pathol 1991;10:15-25.

17 Bast RC, Klug TL, John E, Jenison E, Niloff JM, Lazarus $\mathrm{H}$, et al. A radioimmunoassay using monoclonal antibody $\mathrm{H}$, et al. A radioimmunoassay using monocional antibody to monitor the course of
$\mathcal{I}$ Med $1983 ; 309: 883-7$

18 van Dam PA, Watson JV, Lowe DG, Cox H, Curling M, Shepherd JH. Tissue preparation for simultaneous flow cytometric quantitation of tumour associated antigens and DNA in solid tumours. $\mathcal{f}$ Clin Pathol 1990;43:833-9.

19 Ross JF, Chaudhuri PK, Ratnam M. Differential regulation of folate receptor isoforms in normal and malignant tissues in vivo and in established cell lines. Cancer 1994;73: $2432-43$.

20 Weitman SD, Weinberg AG, Coney LR, Zurawski VR, Jennings DS, Kamen BA. Cellular localization of the folate receptor-potential role in drug toxicity and folate homeostasis. Cancer Res 1992;52:6708-11.

21 Mantovani LT, Miotti S, Menard S, Canevari S, Raspagliesi F, Bottini C, et al. Folate binding protein distribution in $\mathrm{F}$, Bottini $\mathrm{C}$, et al. Folate binding protein distribution in cinoma patients as detected by the monoclonal antibodies cinoma patients as detected by the monoclonal antibod

22 Weitman SD, Lark RH, Coney LR, Fort DW, Frasca V, Zurawski VR, et al. Distribution of the folate receptor GP38 in normal and malignant cell lines and tissues. Cancer Res 1992;52:3396-401.

23 Haisma HJ, Knapp RC, Battaille A, Stradtman EW, Zurawski VR. Antibody-antigen complex formation following injection of I-131-labelled OC 125 monoclonal antibody $\mathrm{F}\left(\mathrm{ab}^{\prime}\right) 2$ fragments into patients with ovarian carcinoma. Int $\mathcal{f}$ Cancer 1987;40:758-62.

24 Boerman OC, Massuger LFAG, Makkink WK, Thomas CMG, Kenemans P, Poels LG. Comparative in vitro binding characteristics and biodistribution in tumor-bearing athymic mice of anti-ovarian carcinoma monoclonal ing athymic mice of anti-ovarian carcinoma

25 Kenemans P. CA 125 and OA 3 as target antigens for immunodiagnosis and immunotherapy in ovarian cancer. Eur $\mathcal{f}$ Obstet Gynecol Reprod Biol 1990;36:221-38.

26 Molthoff CFM, Pinedo HM, Schluper HMM, Nijman HW, Boven E. Comparison of the pharmacokinetics, biodistribution and dosimetry of monoclonal antibodies OC 125 , OV-TL 3 , and $139 \mathrm{H} 2$ as $\operatorname{IgG}$ and $F\left(\mathrm{ab}^{\prime}\right) 2$ fragments in experimental ovarian cancer. $\mathrm{Br} \mathcal{F}$ Cancer 1992;65: 677-83.

27 Kuhnel R, Rao BR, Poels LG, Delemarre JFM, Kenemans P, Stolk JG. Multiple parameter analyses of human ovarian cancer: morphology, immunohistochemistry, steroid hormone receptors and aromatase. Anticancer Res 1988;8: mone

28 Riethmuller G, Schneider-Gadicke E, Schlimok G, Schmiegel W, Raab R, Hoffken K, et al. Randomised trial of monoclonal antibody for adjuvant therapy of resected Dukes' C colorectal carcinoma. Lancet 1994;343: 1177-83. 